микрогруппы, находить формы и способы противодействия этим негативным явлениям.

\section{Список литературы}

[1] "Уголовный кодекс Российской Федерации" от 13.06.1996 N 63-Ф3 (ред. от 27.12.2018) (с изм. и доп., вступ. в силу с 08.01.2019)

[2] Савченко В.М. От неформальных молодежных групп и объединений до молодежной субкультуры «Вестник университета
(Государственный университета управления), № 6(44), 2008, C. $107-113$

[3] Диагностика и профилактика неуставных взаимоотношений между военнослужащими URL: http://armyrus.ru/index.php?option=com_content\&tas $\mathrm{k}=$ view\&id $=167$

[4] Воспитание воинской дисциплины, предупреждение правонарушений и поддержание правопорядка в воинских подразделениях URL:http://www.indbooks.in/mirror1.ru/?p=714885 (дата обращения:02.04.2019)

\title{
ПУТИ ФОРМИРОВАНИЯ КУЛЬТУРЫ ТРУДА МЛАДШИХ ШКОЛЬНИКОВ НА УРОКАХ
} ТЕХНОЛОГИИ

\section{АННОТАЦИЯ}

Джкафарова Оксана Сергеевна канд.пед.наук, ГБОУВОРК

«Крымский инженерно-педагогический университет» г.Симферополь

DOI: $10.31618 /$ ESU.2413-9335.2019.1.64.218

В статье раскрыты основные пути развития культуры труда младших школьников на разных этапах уроков технологии. На основе анализа литературы и практического опыта обозначена необходимость формирования культуры труда как преобразовательной деятельности человека, позволяющей ему участвовать в современных трудовых процессах на основе гармоничного взаимодействия с природой, обществом и технологической средой.

\section{ABSTRACT}

The article describes the main ways of developing the labor culture of children of primary school at different stages of technology lessons. Based on the analysis of literature and practical experience, the need to form a labor culture as a transformative activity of a person, allowing him to participate in modern labor processes on the basis of harmonious interaction with nature, society and the technological environment, is indicated.

Ключевые слова: культура труда, трудовое обучение младших школьников, уроки технологии.

Keywords: labor culture, labor training for children of primary school, technology lessons

В современном мире отмечается тенденция снижения общей культуры подрастающего поколения в целом, поэтому появляется особая необходимость в воспитании культуры труда младших школьников как одного из факторов формирования всесторонне развитой личности, способной к организации и выполнению будущей профессиональной деятельности. Одной из основных задач школы является формирование интереса и любви к трудовой деятельность, ведь учеба для младших школьников выступает ведущим видом деятельности, в которых содержатся истоки раннего выявления способностей, направленности личности, правильного выбора будущей профессии.

Проблема воспитания культуры труда на этапе начального обучения на основе развития интереса к трудовой деятельности (В. Бахир, Н. Бондарева, Т. Коменских и др.), рационализацией учебного труда младших школьников (В. Иванова, П. Мазур и др.). Такие учёные, как П. Атутов, О. Кожина, В. Овечкин, В. Симоненко, Ю. Хотунцев раскрыли сущность и содержание данного понятия, указали проблемы, формы и методы формирования составляющих культуры труда.

В связи с актуальностью данной проблемы целью статьи является раскрыть основные пути формирования культуры труда младших школьников на уроках технологии.

В наше время, явление культуры включает в себя все виды деятельности человека. Под культурой труда, Н. Ф. Бабина понимает уровень развития преобразовательной деятельности человека, выраженный в совокупности достигнутых технологий материального и духовного производства и позволяющий ему эффективно участвовать в современных трудовых процессах на основе гармоничного взаимодействия с природой, обществом и технологической средой [1]. Таким образом, суть данного понятия предполагает новый взгляд на окружающую действительность, который выражается в преобразовании и совершенствовании мира, в котором живут люди.

Фундаментальной составляющей культуры труда является преобразовательная деятельность людей, через которую проявляются их творческий потенциал, знания и навыки. Преобразовательная деятельность присутствует во всех сферах жизни людей, а также во всех сферах их трудовой деятельности [2].

Период младшего школьного возраста является наиболее благоприятным для воспитания культуры труда, так как именно в данном возрасте существует потребность в осознании самого себя, 
как необходимого и значимого члена общества, способного к преобразованию окружающего мира путём собственной трудовой деятельности, что влечёт необходимость в овладении правилами организации, проведения и реализации поставленных трудовых целей [Конышева].

Учебный предмет «Технология» выступает важной средой для формировании культуры труда, так как включает в себя множество видов работы, которые требуют определённого порядка её выполнения, организации собственного рабочего места, умения взаимодействия с окружающими, учат экономии собственного и чужого времени, что является составляющими рассматриваемого нами явления. Для того, чтобы работа по формированию культуры труда на уроках технологии в начальных классах прошла наиболее успешно, необходимо выполнять определенные условия на всех этапах урока технологии.

В самом начале, до урока ученику необходимо проверить готовность рабочего места. Для этого, учитель предварительно проговаривает с какими именно материалами и инструментами ребятам придется работать. Целесообразно хранить все художественные материалы для уроков в классе, в специальной папке - это хранение в папках на резинках, внутри которой существуют отдельные ячейки для инструментов и материалов. Кроме этого ученикам необходимо помнить об использовании клеенки для стола, которая защитит парту от загрязнений. Перед уроком ученик одевает специальную одежду (фартуки, халаты, нарукавники), которые предохранят их одежду от загрязнения. Так же им пригодятся влажные салфетки для рук.

Очень важно приучить детей следить за порядком на рабочем месте в течение всего урока. Например, инструменты и материалы, которые ученик берет правой рукой, полагается класть с правой стороны, а те, которые удобнее брать левой рукой - с левой. Такая работа проводится учителем планомерно в течение всего периода обучения, для отработки навыка учащихся. Помочь детям в этом могут различные игры и пословицы, например, «Кто быстрее переложит инструменты с одной стороны на другую», «Помоги другу навести порядок» и другие.

Также следует обучать детей экономному расходованию материалов. Но это должна быть не просто словесная работа учителя. Необходимо на собственном примере ребятам показать варианты рационального использования картона, бумаги, ткани. Например, удобное расположение шаблонов на бумаге, размещение выкроек на ткани. Целесообразно провести урок по изготовлению панно из таких оставшихся кусочков бумаги или ткани для наглядного примера. По окончании работе можно устроить соревнование на количество обрезков у каждого ученика.

Важно предупредить ребят о последствиях неправильного обращения с режущими и колющими предметами и инструментами. Например, могут возникнуть травмы при резании ножницами, при работе с циркулем, швейной иглой. Обязательное выполнение правил техники безопасности предупредит учащихся от несчастных случаев. Знакомить детей и говорить об этом необходимо с первых уроков. Также обязательно постоянно проводить короткие инструктажи по изучению правил.

Традиции поведения учащихся на уроке складываются постепенно, с 1-го класса. Происходит формирование нравственных привычек: обязательности, трудолюбия, ответственности, добросовестности, желания работать с полной отдачей сил и с хорошим качеством, умения уважать свой и чужой труд, ценить время, соблюдать правила техники безопасности и дисциплину [].

Ни о какой воспитательной работе не может идти речь, если на уроках нет дисциплины. Не той дисциплины, которая построена на авторитаризме, на окриках и наказаниях, а сознательной дисциплины, предполагающей соблюдение общепринятых норм поведения: не опаздывать на уроки, выполнять свои обязанности без напоминаний, не мешать другим выполнять работу и т.д. Именно из этого, в первую очередь, складывается культура труда младших школьников. Настоящая дисциплина есть активное устремление соблюдать нормы поведения, которые уже делаются «второй натурой», побуждают в человеке корректировать свои поступки без дополнительных стимулов.

Своеобразие педагогической работы по воспитанию культуры труда у учащихся в качестве главного принципа предполагает учет индивидуальности каждого. Суть воспитательной теории исходит из положения о том, что человек есть часть социума, формирующая себя самого. А потому важной стороной изучаемого процесса является и внутренняя психическая структура личности ребенка, а также характеристика и особенности процесса его индивидуализации [5].

Дети неодинаковы, и нельзя одинаково оценивать деятельность и ее результаты у каждого отдельного школьника. Многие неудачи педагогической деятельности по воспитанию культуры труда обусловлены отсутствием действительно дифференцированного подхода к учащимся. Отношение школьника к труду, его интересы и желание трудиться, чувства и направленность труда, трудовые ценностные ориентации создают неповторимое своеобразие личности и определяют весь ход и результаты воспитательного процесса. Поэтому при организации трудовой деятельности как эффективного пространства и фактора воспитания культуры труда в соответствии с дидактическим принципом сочетания групповых, массовых и индивидуальных форм работы в каждом конкретном случае педагогу надлежит находить наиболее рациональную меру дифференциации и персонификации педагогических воздействий. Эта мера проявляется в дифференциации объема и сложности предлагаемых учебных и трудовых 
заданий, в предоставлении школьникам большей или меньшей самостоятельности.

После завершения работы обязательна самостоятельная уборка рабочих мест. Каждый ученик должен самостоятельно убрать на место инструменты, выбросить отходы, материалы сложить в конверты и коробки, упаковать одежду, свернуть и убрать клеенку. Интереснее такую работу ребятам выполнять под счет, куплет песни, или соревнуясь друг с другом.

Период формирования культуры труда у младших школьников является наиболее значимым. Большинство школьников приходят в школу, не обладая никакими представлениями ни о трудовой деятельности, ни о правилах, ни о способах, ни о важности её проведения: они любят отдельные работы только на словах и практически их не осуществляют. Их любовь к труду оказывается не связанной с практикой. К моменту окончания школы они должны любить труд не на словах, а эмоционально осуществлять это на практике.

Таким образом, процесс воспитания культуры труда может быть эффективным лишь при одновременном действии всех факторов, определяющих весь ход подготовки учащихся к жизни и труду. Педагогическое обеспечение этого процесса должно быть направлено на раскрытие и использование возможностей содержания, форм и методов включения учащихся в различные виды практической деятельности на уроках технологии.

\section{Список литературы:}

1. Бабина Н.Ф. Технология: методика обучения и воспитания. Часть I. - M.: DirectMEDIA, 2015. - $162 \mathrm{c}$.

2. Выгонов В.В. Практикум по трудовому обучению. М.: Академия, 2009. - 256 с.

3. Конышева Н.М. Теория и методика преподавания технологии в начальной школе. Смоленск: Ассоциация XXI век, 2006. - 296 с.

4. Гомырина Т.А. Развитие творческих способностей первоклассников на уроках художественного труда. М.: ВЧГК «Русский Центр», 2010. - 186 с.

5. Николаенко Н.Н. Методические рекомендации по проведению уроков трудового обучения в начальных классах. М.: ЦГЛ, 2003. - 300 c.

ФИЗИКАДАН ЕСЕП ШЫҒАРУ БІЛІКТІЛІГІНІҢ ПСИХОЛОГИЯЛЫҚ, ПЕДАГОГИКАЛЫҚ НЕГІЗДЕРІ

\author{
Кенжегалиев Кулуш Кушенович \\ педагогика выл. канд., \\ педагогика, психология \\ және әлеуметтік жұмыс кафедрасының доиенті, \\ Көкшетау қ.. Казақсттан. \\ Алмаханов Шыцдыс \\ 2 курс магистранты, Көкшетау құ., Казақсстан
}

PSYCHOLOGICALY-PEDAGOGICAL BASES OF SKILLS TO SOLVE PHYSICAL PROBLEMS

\author{
Kenzhegaliev Kulush Kushenovich \\ PhD in Pedagogy, \\ assistant professor of the Department of Pedagogy \\ and Psychology and social works of Kokshetau \\ State University named after Shokan Ualikhanov, \\ Kokshetau, Kazakhstan \\ Almakhanov Shyngis \\ 2nd year master student, Kokshetau, Kazakhstan
}

\title{
АННОТАЦИЯ
}

Мақалада молеклалақ физикадан есеп шығару біліктілігін психология ғылымдары, оның теориялары арқылы зерттеп қиын жерлерін тауып жаңа әдіс ұсыну. Зерттеу әдістері психологиялық заңдарға негізделіп, оқытушының психологиялық құзыреттілігін қалыптастыру. Оқытушы оқушыларға есеп шығарғанда есептің шығару психологиясына көңіл бөлмейді. Ол үшін педагог кадрларды дайындағанда әр пәннің психологиясын қатар оқыту ұсынылып отыр. Оқыту дегеніміз оқушының психикасын есеп шығару арқылы басқару, қалыптастыру болып табылады. Эксперимент барысында есеп шығарудың бес деңгейі анықталды. Оқушылардың басым бөлігі 2,3 деңгейде шығарады. Осы олқылықты жою мақсатында мақаланың зерттеу пәні осыған арналған.

\section{ABSTRACT}

This article explores the ability to solve problems on molecular physics with the help of psychological science, using its theory to identify difficult solving problems and to suggest new methods.

The process of researching the problem of solving tasks is entirely based on the laws of psychology with the simultaneous formation of the psychological competence of the teacher. 